\title{
1. Setting the agenda on agenda setting: definitions, concepts, and controversies Nikolaos Zahariadis
}

In his Third Olynthiac, the Athenian orator Demosthenes implores his fellow Athenians to follow his advice and immediately send (enough) troops to help the Olynthians in their fight against King Philip II of Macedon. Demosthenes was well aware that democratic collective action required persuasion, decision-making, and implementation. So he used both reason and emotional appeal to link individual aims to collective objectives and steer policy decisions in the direction of war. While his speeches are still considered to be masterpieces of oratory and political realism, the orator eventually failed to achieve his purpose, not because his fellow Athenians were not moved by his fiery rhetoric but because they did not share his conviction that Philip was their biggest problem and immediate priority. And even when they sent troops, they ended up doing too little, too late. Establishing priorities is clearly as important as deciding what to do about them.

Fast-forward twenty-three centuries, and in his problem orientation and the policy sciences Harold Lasswell (1951) somewhat similarly calls for democratic collective action to use reason (not emotion) and science to solve man's greatest problems. He, too, understood the importance of careful observation and reason in pursuit of collective objectives. While Lasswell was more successful in his pursuit than Demosthenes, he still had to answer the same question: what are man's greatest problems? His response involved two components. First, man's greatest problems are the most important, fundamental, but not necessarily most urgent issues of the day $(1951,8)$. In other words, the policy sciences encouraged a steady stream of solutions to non-urgent social problems. Second, solutions and problems were causally linked through ordered values. The goal of policymaking was to produce the type of affairs we find most desirable: prosperity rather than poverty, peace rather than war, and so on. Beyond that, Lasswell still faced what may be termed as the Demosthenian predicament. While he was deeply aware of the importance of politics in policymaking, he still assumed there would be some form of collective consensus on important priorities. But if there is no consensus on today's priorities that urgently need to be addressed for their immediate consequences, how 


\section{Handbook of public policy agenda setting}

can there be consensus on issues that might become tomorrow's urgent priorities with uncertain long-term consequences?

It took almost a decade for scholars to begin articulating the detachment of public problems from political priorities and its implications for democratic politics. Two seminal works drove the point home. Criticizing the prevailing pluralist approach, Bachrach and Baratz (1962) conceptualized the study of governmental decision-making as consisting of two dimensions: winners and losers. Policies reflect not only the preferences and power of those groups whose problems have been addressed but also the ability of the same groups to limit subsequent institutional attention to only those issues that reinforce or augment the status quo. They observed that some institutions were imbued with certain values that make some points of view difficult, if not impossible, to hear. How democratic is that? While political systems may be designed in ways that eschew the problem of "the superior force of an interested and overbearing majority," as Madison expressed so well in Federalist \#10, it is also possible to limit the scope of the process to only "safe" issues. Hence it is perhaps more important to study "non-decisions" to get a glimpse of what values or demands are precluded from becoming institutional priorities (Bachrach and Baratz, 1963).

In what may be arguably the most insightful short book ever written about politics, Schattschneider (1960) similarly observes that political systems are inherently biased. In a memorable phrase, he claims: "the flaw in the pluralist heaven is that the heavenly chorus sings with a strong upper-class accent" (35). In terms of policymaking, this statement implies the democratic system, as designed in the United States because that was his focus (but it surely applies elsewhere as well), is loaded and unbalanced in favor of those in power. The problems that government institutions address, argues Schattschneider, tend not to be fundamental, universally desirable issues ("man's greatest problems") but rather those that interest and affect the elites and the well-organized. Democracy is turned on its head by carefully regulating conflict and suppressing unwarranted demands. Because policymakers are assumed to be controversy avoiding, satisficing vote-seekers, they are predisposed toward addressing short-term issues rather than long-term problems: actions already taken because they are relatively uncontroversial, rather than novel solutions that may generate controversy (Braybrooke and Lindblom, 1963). With some exceptions, problems and solutions tend to marginally deviate from the status quo in a process of mutual adjustment that regulates political tension.

Why, then, is the study of setting policy priorities important for students of public policy? There are five good reasons. 
First, studying the agenda as a list of priorities helps us understand social values. For example, the emergence of pollution as a US public problem in the late 1960s tells us something about prevalent social values at the time relative to, say, the early 1900s. The point is not that pollution did not exist prior to the 1960s but that it was not an issue worthy of widespread public attention prior to that decade.

Second, specifying the agenda illuminates potential gaps between government and the public in democratic and non-democratic societies alike. For example, the deplorable state of the environment in Eastern Europe after the fall of the Berlin Wall revealed lack of citizen voice and complete government apathy to the quality of life of ordinary citizens. Attention to environmental concerns since the 1970s in Germany demonstrates relative improvement in government attention to citizens' concerns.

Third, by their very existence priorities create political winners and losers. Because there is no society-wide consensus on what government should address first, except for big issues such as war, agendas reflect the priorities of some groups and not of others. For example, the fact that school gun violence - such as the massacre at Sandy Hook Elementary School in Connecticut in 2012 - did not have traction on the government agenda (in the form of attracting attention for a long period of time) says something about what groups are powerful and in what ways.

Fourth, agenda setting profoundly affects policy decisions. This is because the agenda provides an imperfect glimpse of what policy options may be adopted. More often than not, politicians want to debate issues they can do something about and define them in ways that favor their pet solutions. This does not mean any one person or institution controls the process, but it does tell us that how issues are defined makes a difference in where they are on the list of priorities and how the issues are likely to be addressed.

Fifth, agenda setting imbues meaning and importance to individuals and institutions beyond any that is formally assigned by constitutional or other legal rules. It structures voters' way of thinking about the world by selectively presenting, analyzing, and interpreting information. Moreover, the institutions to which individuals turn to receive and analyze information tend not to be assigned formal political power. For example, democratically unaccountable institutions - such as major newspapers, television broadcasts, the Internet, and the plethora of blogs - and individuals - such as journalists and other opinion-makers - are able to shape public policy in fundamental ways; "the mass media may not be successful much of the time in telling people what to think, but it is stunningly successful in telling its readers what to think about" (emphasis in original; Cohen, 1963, 13, cited in McCombs and Shaw, 1972, 177). 


\section{Handbook of public policy agenda setting}

Understanding how the agenda is set, when, and by whom is a necessary step to comprehend how policy is made.

In this introduction, I set the agenda on the study of agenda setting. I first define terms to clarify the concepts and processes involved. I then proceed to spell out what I consider to be the three path-breaking works that have marked agenda setting research. The field is lucky in that it is relatively new and small, so path-breaking studies can be identified and explained. Finally, I spell out the aim and plan of this Handbook. What makes it unique and different from other handbooks is not simply its novelty but also my concern with including four aspects of public policy: ideas, institutions, insight, and individuals. I strongly believe that institutions make wonderful ideas possible, but individuals make things happen. Ensuring some attention to foundational works and individuals gives me the pleasure of placing insight and ideas into institutional context.

\section{DEFINITION OF TERMS}

Before proceeding any deeper into the nuts and bolts of agenda setting, it is imperative to define the terms that will be used. In this way we can make subtle differences more distinct and explicit when we actually review theoretical approaches to agenda setting.

The term "agenda" did not appear in the policy sciences literature until Roger Cobb and Charles D. Elder (1971) published a brief article in the Journal of Politics, ${ }^{1}$ in which they hit on the main points of their upcoming book, Participation in American politics (1972). They define the term agenda as "a general set of political controversies that will be viewed as falling within the range of legitimate concerns meriting the attention of the polity" (Cobb and Elder, 1971, 905). They also conceptualize an institutional agenda "to denote a set of concrete items scheduled for active and serious consideration by a particular institutional decision-making body" (906). They then proceed to build an explanation of how and why issues move from the former (the systemic agenda) to the latter (the institutional agenda). Kingdon (1984) adds one more type of agenda, the decision agenda, which refers to a shortlist of items on the institutional agenda that receive serious and immediate consideration.

Yet another stream of research in political communication defines the term "agenda" as a list of issues the public considers important (McCombs and Shaw, 1972). Inspired by Walter Lippmann's (1922) argument that the media shapes public opinion by creating "pictures in our heads," scholars following this tradition differentiate between three agendas. First, they focus on the public agenda (Cobb and Elder's systemic agenda) 
and how it is shaped. Second, they focus on the media agenda (what the media considers to be the important issues of the day) and how it shapes and is shaped by the public agenda. Finally, they focus on the policy or political agenda (what elites consider to be the most important issues) and how these preferences influence public policy (Rogers and Dearing, 1988). There are clearly many agendas and we need to put some order to the definitions, otherwise we will end up using similar terms but talking past each other, a phenomenon that is well-known and widespread in academic discourse.

Although contributors to this Handbook have been given latitude to define terms in the way that they deem appropriate, the term "agenda" here generally refers to a contextual list of actionable government priorities. There are four important elements to this definition: context, actionable, government, and priorities. Starting backwards, the most important thing about any agenda is the fact that it reflects some form of ordering or prioritization. The entire literature depends on an assumption that is unfortunately rarely made explicit: attention is scarce and therefore individuals as well as institutions have to establish priorities. Priorities are items that are considered to be the most important and that need to be urgently addressed. They may include the war in Syria, race relations, the federal budget, or poverty, among others. Obviously many factors go into this ordering process, such as values, roles, institutional perspectives, and so on. Moreover, there is frequently no "written" list of what the priorities are, which makes it more or less a guessing game of epiphenomena. This means we can only guess what is being considered from what important people tell us and what actions are taken; as such, as non-participants we usually determine what the agenda is after decisions have been made.

Scholars in this Handbook have been asked to deal primarily with the political or government agendas. While the media's role is important in shaping public opinion, as policy analysts we are interested primarily in how issues move from the systemic to the institutional agenda (Cobb and Elder, 1972) or how they climb from the institutional to the decision agenda (Kingdon, 1984). This movement can be affected by many factors such as the media, interest groups, or natural or man-made disasters.

We focus primarily on actionable items. More than any other scholar, Kingdon (1984) sensitized the entire literature to the fact that agendas are more than just a cacophony of private and public issues. They involve more than mere laundry lists of issues that groups, institutions, or individuals consider "fit to print" (as The New York Times' motto asserts). They involve some type of filtering process that depends not only on the values of the actors involved but also on the degree of actionability. The point is not that all agendas will focus only on actionable items but that serious 
consideration will be given primarily to those items that policymakers believe they can affect. Perception is key because it is possible to build agendas that also include symbolic items, which are issues that policymakers know they cannot - or naively believe they can - address but which policymakers include because they want to placate supporters or to deflect attention from what they really want to accomplish. If agendas are about forming priorities, actionability in addition to values and accessibility are key ingredients of the filtering process.

Finally, we zoom in on context. Be they systemic, institutional, or decision, agendas are social artifacts and must be examined in context. What is considered to be an important issue differs over time and across societies not only as a matter of preference but also as a matter of dynamics. The process by which agendas are set differs because of institutional and cultural variations, making it a politically fluid and dynamic process. Consequently, agendas must be evaluated within (or across) given societies and carefully circumscribed by particular temporal periods.

In their original formulation, Cobb and Elder (1972) used the term "agenda-building" to denote the process by which issues are placed on the list of political controversies in a given community. They ask where public issues come from and why some controversies come to command attention from government institutions while others fail to do so. At the heart of their argument is a conflict management perspective. For our purposes, and following the evolution of the literature, we use the term "agenda setting." Agenda setting is defined as the process of turning public issues into actionable government priorities. We combine the preoccupations of Cobb and Elder and those of Kingdon with the three agendas into a quest for understanding the process of movement. It is a process that is fundamentally shaped by cultural, institutional, temporal, and political biases and inertia. The task is not only to tease out the roles that various actors and institutional contexts play in the process but also to model the dynamics of issue movement at variable speeds - which may include amendment, recombination, or deletion - through various agendas toward becoming (or not becoming) government's higher priorities.

It should be noted that political communication theory also uses the terms "agenda setting" and "agenda building" but they refer to different processes. According to Rogers and Dearing (1988), "agenda setting" refers to the effect of the media on determining the priorities of public opinion, while "agenda building" refers to the interactive relationship between the media and society at large in shaping the list of importance. Given the policy focus of this Handbook, we will use the definition of agenda setting offered by combining the ideas of Cobb and Elder, and those of Kingdon, which are more widely accepted in the policy sciences. 


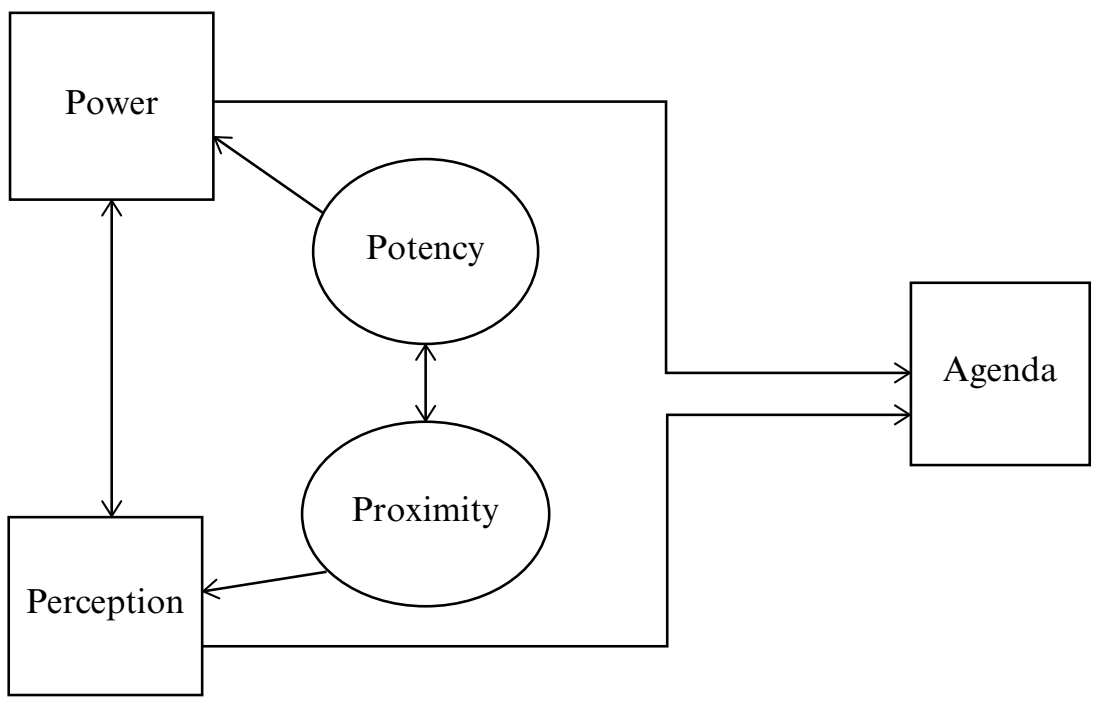

Figure 1.1 The four "P"s of agenda setting

\section{THE FOUR “P”S OF AGENDA SETTING}

Stripped to its essentials, the process of agenda setting contains four fundamental elements, which may be termed "the four 'P's." Theoretical attempts to model the process assign different values and importance to each element but they all address them in some capacity. Figure 1.1 presents a version of this idea schematically. In this section, I briefly discuss the four elements to make the subsequent account of theoretical models more comprehensible and meaningful.

Power is perhaps the most important element of agenda setting. If actionable items are the result of political contests, the power to manipulate, persuade, prevent, or coerce may resolve these contests. Actionable government priorities reflect the power of some groups or individuals over others in making their voices heard (or preventing others from being heard) and by implication turn their own parochial concerns into public problems that need to be collectively addressed. For example, the bailout of financial institutions worldwide in 2008 reflected the power of big financial institutions to convince governments to "nationalize" private losses. Moreover, placing an item on the systemic agenda is not enough. What is needed is movement across agendas, from systemic to institutional (government) to decision. Such movement often necessitates the power to persuade that some items are worthier of government action than others. 
How power is exercised and when are matters of theoretical reflection and empirical validation.

Perception crucially affects what issues are deemed important and why. While many issues deserve government attention at any given time, only few of them become public problems. The process of turning issues into problems contains a perceptual element (Kingdon, 1984). Quite often policymakers, opinion makers, and other personalities of public life selectively report and interpret events so as to activate (or deactivate) empathy or support for an item. For example, in order to activate public support for the invasion of Iraq, the first George W. Bush administration employed journalists to write favorable news reports, which were then distributed to news outlets. The plight of refugees crossing the Aegean Sea into Greece received widespread media attention (and subsequent government action) only after pictures of the drowned three-year-old Aylan (later clarified by his father as Alan) Kurdi appeared in newspapers (Smith, 2015). His lifeless body, washed up near the resort of Bodrum, revealed the human tragedy unfolding off the coast of Turkey and galvanized public opinion into action. Horror and perceptions of the loss of humanity fuelled attention to the dangers that the refugees faced, turning a personal tragedy of several hundred thousand non-Europeans into a major European actionable priority.

Potency refers to the intensity or severity of consequences of a given issue. In general, the greater the intensity or severity of consequences, the more salient the issue(s) will be on the government's agenda. For example, the events of 9/11 had an enormous effect on American politics. They brought to the fore numerous and highly diverse issues ranging from civil rights to government reform to airline subsidies, defined in ways that were not possible before (see, for example, Birkland, 2004). In contrast, although it was also an act of terrorism, the explosion of Pan Am Flight 103 over Lockerbie, Scotland in 1988 had a lesser impact in terms of number or severity of issues raised. The difference in terms of human casualties (2,977 versus 270 , respectively) and the sheer number of subsequent changes (in terms of civil rights, security, and aviation versus security only, respectively) is striking. Clearly, the potency of $9 / 11 \mathrm{had}$ a more profound, wider, and longer-lasting impact on the government's agenda.

People are more likely to pay attention to issues that seem to have a more direct and (geographically or temporally) more proximate impact on their own lives. The more direct or closer the impact, the greater the attention the issue is likely to receive. This is the essence of Tip O'Neill's famous quip: "all politics is local." Proximity to people's lives - safety, prosperity, and so on - profoundly shapes their attention. For example, it took the Obama administration several years to declare the Islamic 
State of Iraq and Syria (ISIS) a major threat to US national security. It is highly unlikely it would have taken this long if ISIS were operating in a neighboring country, such as Mexico, as opposed to Syria.

The variables have both direct and interactive effects. Within a given institutional setting, power configurations and perceptual bias color the placement of issues and their movement across agendas. For example, political contests to bring attention to immigration concerns are shaped by the constellation of powerful interest groups and their perception of how immigration affects their livelihood, in terms of both safety and prosperity. Assuming all else remains constant, changes in power configurations or perceptions will lead to movements up and down the agenda. But each variable also affects the other(s). Power shapes perception to an extent in that some issues, such as diversity, tend to be more salient to opposition groups precisely because they are not in power. Similarly, perceptions of friends and foes shape the nature of political coalitions and consequently may lead to reversal of political fortunes.

Proximity and potency have indirect effects on the agenda as they are filtered through power and perception. For example, the outbreak of the Ebola epidemic in West Africa in 2014 may be viewed as a major concern in distant lands, which does not merit American government attention. However, one may also perceive the outbreak as an imminent and direct health risk to American citizens if one considers the speed and abundance of different modes of transportation to and from these countries. That is precisely the process by which the Zika virus in Brazil gained American attention in 2016. The effects of potency are similarly filtered through power and perception. For example, the catastrophic effects of Hurricane Katrina on poor neighborhoods in New Orleans, Louisiana were not immediately evident; hence, the issue was not defined as a "poverty" catastrophe but rather as a federal response failure. Similarly, systematic police brutality generally does not receive much public scrutiny if it is largely confined to minorities and poor neighborhoods (Holmes and Smith, 2008), with a few exceptions such as Ferguson, Missouri.

The process of setting the agenda includes some configuration of links between the four "P"s. While different theoretical models may add more variables and specify alternative relationships to the process, they all have to address the four " $\mathrm{P}$ " ingredients in some way. How precisely some do that is the topic of the next section. 


\section{AGENDA BUILDING AND POLITICAL CONFLICT MANAGEMENT}

It is perhaps comprehensible that the need to study agenda setting would become obvious in the turbulent decade of the 1960s. Democratic reality simply did not appear to live up to its promise. A system that seemed deaf to popular demands, blind to abject poverty among certain groups, and systematically mute to popular participation could not cope effectively with radical policy change. The study of agenda setting was therefore proposed as a way of understanding issue conflict and power, as an explanation of radical change, and more importantly as a means of mass participation in democratic politics.

Driven by the need to reconcile democratic theory and actual practice in the United States, Cobb and Elder (1972) sketched out a model of agenda building that aimed to explain where public controversies came from and why some made it onto the government docket as legitimate political controversies while others did not. At the heart of their explanation lies Schattschneider's (1960) observation about issue conflict expansion. Their fundamental premise is that "issue expansion to larger publics acts as the prelude to formal agenda consideration" (Cobb and Elder, 1972,160 ). Issues arise out of group conflict (how to distribute positions or resources) and gain access to decision-makers by expanding in scope, potency, and proximity. Issues that are broader in scope - that is, they are more ambiguous, less technical, of higher social significance, and of longer temporal relevance - are more likely to reach larger attention groups or attentive publics than others. Issues that use more urgent, credible, and potent symbols are more likely to gain access to decision-makers. Finally, the more durable an issue and the larger the public - that is, the more intimately the issue reaches higher numbers of people - the greater the likelihood will be to gain access to the institutional agenda.

Apart from perhaps single-handedly creating a new field of the study of pre-decision processes, Cobb and Elder made two of the most important contributions to the study of agenda setting. Going back to Lasswell's (1951) original view of the policy sciences as the cornerstone for democracy, the authors' first contribution $(1971,1972)$ was their preoccupation with problems of political power and democratic theory. Whereas conventional wisdom of the day assumed a relatively well-functioning pluralist system whereby pressure groups freely compete for resources and attention, Cobb and Elder noted that this was not only an institutionally manufactured myth, but also that it aimed to preclude mass participation because such participation was deemed to be detrimental to democratic politics. Their framework therefore aimed to explain and 
prescribe democratic agenda access. At an explanatory level, they tried to understand why some issues would gain traction. Understanding the dynamics of the process would then enable groups to devise ways to access the agenda at a normative (practical) level. Whereas some scholars, such as Huntington (1968), argued that mass mobilization inevitably created gaps between expectations and outcomes with detrimental consequences for democracy and stability, Cobb and Elder saw mass mobilization as a tool to give access to legitimate grievances in order to prevent repression and instability.

Their second contribution was to extend the argument in a comparative direction (Cobb, Ross, and Ross, 1976). Much of the evidence marshaled in support of their claim was built on community and local settings in the United States. In an effort to broaden its appeal to other audiences, they carefully generalized to other national settings, creating a research agenda that remains unfulfilled to the present day.

\section{ATTENTION AND AGENDA SETTING}

In contrast to the conflict management perspective of Cobb and Elder, John Kingdon (1984) authored the most frequently cited book on agenda setting, adopting insights from organizational theory and evolutionary biology. He downplayed aspects of issue conflict and expansion and instead focused on ambiguity, perception, and policy entrepreneurship.

Kingdon built a framework of agenda setting inspired by the garbage can model of organizational choice (Cohen, March, and Olsen, 1972). It conceptualized a system based on temporal sorting: issues rising to the top of the agenda depend largely on what else is happening in the system and who is pushing the item and how. The fact that government systems are plagued by ambiguity, defined as a state of having many unclear and irreconcilable ways to interpret issues (Zahariadis, 2014), creates two distinct dynamics. The first dynamic refers to three streams of problems, policies, and politics. Each stream is assumed to be largely independent of the other, obeying its own structural rules and shaping which item will bubble to the surface and which will not. For example, not all policies are equally likely contenders in what Kingdon (1984, chapter 6) called the "primeval soup of ideas." The ideas most likely to receive attention tend to be technically feasible, have spent a long time "softening up" among members of relevant policy communities, and are less costly than others. Issues become problems when they are accompanied by focusing events, such as a flood or a hurricane, or when they are categorized in specific ways: a process that Schattschneider (1960) called "redefinition." 


\section{Handbook of public policy agenda setting}

The second dynamic refers to how and when the streams interact. To make this process more comprehensible, Kingdon (1984) added two more elements: policy windows and policy entrepreneurs. In contrast to the literature on agenda setting up to that time, Kingdon (1984) argued that movement within and across agendas was also intimately linked to windows of opportunity. Context was critical in understanding the process because issues carry more weight than others at certain points in time. Making this argument enabled Kingdon (1984) to theorize the importance of timing in policymaking. Not everything can be connected to everything else, and policy windows, which open either in the problem or politics streams, make some linkages more possible than others. For example, the gunning down of students in Sandy Hook Elementary School in Connecticut brought the issue of gun availability to public and government attention. This created a more propitious context in which to pay closer attention to the problem of gun control. The greater the potency of the event - in this case the number of dead children - the more likely the issue is to gain access to the institutional agenda. Similarly, the election of a new Republican administration brings to the foreground the issue of lower taxes that a Democratic administration would be reluctant to tackle.

The concept of "policy entrepreneur" is Kingdon's most important contribution because it gives an element of agency to models that had previously been more structural in orientation. Items rise to the top of the government agenda during open policy windows, when key actors join two or more streams together. The likelihood that an issue will move to the decision agenda increases when all three streams are combined. Quite often the process changes direction, meaning that solutions often chase problems as they are amended, combined, and adapted to the problems of the day.

Kingdon (1984) moved away from problems with democratic theory and adopted a more social scientific perspective, which focused on specifying the dynamics of attention. He was able to combine agency and structure in a theoretically meaningful way. He also linked macro-institutional developments, which certainly play a major role in setting the federal government's agenda, to sectoral developments in policy communities in which only specialists usually participate. Assuming a heavy dose of serendipity, he also pushed the boundaries of agenda setting by sensitizing scholarship to the bias of actionable issues. Vote-seeking policymakers are more likely to suppress attention on issues such as poverty because they can do relatively little about ameliorating the situation. As such, they focus more on cutting taxes -something they can control - than on the consequent implications of budget cuts on poverty - something they cannot. 


\section{THE POLITICS OF ATTENTION AND INSTITUTIONAL FRICTION}

Cognizant of the limitations of the works of Cobb and Elder $(1971,1972)$ and Kingdon (1984), Baumgartner and Jones (1993) wrote a book that theorized the rise and fall of issues on the agenda through periods of stability and punctuation. They borrowed from Kingdon (1984) the focus on policy entrepreneurs, perception, and ambiguity and from Cobb and Elder $(1971,1972)$ the focus on the media, power, and issue conflict expansion. Like Kingdon (1984), their argument still problematizes agenda setting as fundamentally a process that politically allocates attention (Jones and Baumgartner, 2005). However, the key differences are the added dimension of institutional power and the notion of venue shopping.

Issues rise and fall on the agenda based on the notions of attention allocation and institutional friction. Because attention is scarce and the number of potential issues too great, policymakers necessarily have to prioritize and interpret information. They do so aided by institutional inertia and friction. To understand how the process works, the authors zoom in on institutional information processing and more specifically the notion of feedback. Borrowing from systems theory and psychology, they hypothesize that issues tend to be sticky in the sense that people are disproportionate information processors; in other words, people process information by selectively attending to those elements that conform to previous beliefs and preferences. They then construct and prioritize interpretations of policy images; that is, perceptions of policies and their implications. In this sense, it is very difficult for new issues to gain access to the agenda because most attention tends to be focused on areas of expertise, as well as in ways that do not deviate substantially from this expertise. Furthermore, institutions add "drag" by imposing costs (collaborations, resources to build coalitions, and so on). Drag is also affected by proximity; non-proximate issues tend to produce more drag in the form of resources needed to generate attention. This process tends to favor positive feedback in American policy communities, essentially implying a dynamic that benefits minor deviations and similar issues over time.

However, the process of stability also encourages mobilization elsewhere in the system. Because of limited attention, when policymakers attend to problems of health care, they necessarily leave transportation problems off the docket. When they turn their attention back to transportation, issues have become bigger, emotions stronger, and mobilization harder to resist because of neglect. Some groups are able to manipulate the system and switch institutional venues. This means they bring issues to the attention of different institutions that may be more sympathetic to their 
views, changing the dynamics of stability described above and introducing an increased likelihood of success. Venue shopping takes place within policy communities but punctuations are more likely to occur when macro institutions, such as Congress, get involved. This is because they introduce new faces, rules, and preferences in positions of authority, altering the dynamics of stability built into the system and introducing an element of punctuation. Punctuations may come in the form of new issues gaining access to institutional agendas or in the form of major error-corrective swings back to old positions that had been "forgotten" after years of positive feedback.

Baumgartner and Jones (1993) present a model of agenda setting that enriches the concepts of power and perception and adds two benefits to the literature. The first benefit is that their approach can employ sophisticated quantitative techniques. In contrast to previous efforts, which relied on qualitative evidence and theorizing, the punctuated equilibrium hypothesis can accommodate both quantitative and qualitative evidence with analytical rigor. The second benefit is theorization at an abstract level to enable comparative investigation. Even though evidence initially drew from the US experience to explain the process of agenda setting, it has been used comparatively to generate and test hypotheses and amendments (Baumgartner, Jones, and Wilkerson, 2011).

\section{AIM AND PLAN OF THE $H A N D B O O K$}

The aim of this Handbook is to introduce readers to the agenda setting approach to public policy. I have assembled a group of scholars from two continents with the intent of providing the best and most up-to-date literature in the field. The ultimate goal is to take stock of various perspectives, identify analytical gaps, showcase good empirical scholarship, and suggest possible avenues for further research. The task of the Handbook is to provide a roadmap to the literature and suggest ways to improve our understanding of how policy works and how the agenda is set. The editor is agnostic about what perspectives are better than others and in what ways. Contributors have been asked to discuss both strengths and limitations.

The agenda setting approach refers to utilizing perspectives that explain pre-decision processes to address broader developments in public policy. It places attention at the center of political action and aims to attribute policy change (or lack thereof) to shifts in attention (Green-Pedersen and Walgrave, 2014). It also aims to explain how the process occurs and for what purpose. The task is multidisciplinary, in that it enlists the aid of a 
number of disciplines - such as psychology, political science, sociology, public administration, and economics - in the true spirit of policy sciences. It is multidimensional, in that it links variables at three levels of analysis: the micro, the meso, and the macro. The micro foundations of attention (after all, only individuals pay attention) build on insights borrowed from psychology, especially cognitive and affective theories. The meso elements involve various forms of organizing - such as interactions among political parties, interest groups, and government agencies - which are the province of several disciplines: political science, sociology, and public administration. But this ecology of interactions takes place within well-established macro-rules and processes that bound and shape individual and group preferences and limit the range and nature of demands. Here, the logic of efficient aggregation and disaggregation, which is well developed in economics, is of paramount importance. At the same time, attention is cognitively and institutionally limited - we cannot attend to everything all the time, hence the need for priorities. The last point makes it clear that the process is contextual and biased, as political scientists since Schattschneider (1960) have suggested. Moreover, the dynamics of attention imply prospective thinking as issues become problems partly based on estimates of potency, proximity, and future consequences, which links pre-decision processes to the rest of the policymaking process, especially implementation. In other words, the agenda setting approach in public policy provides an important (but not the only) way of realizing Lasswell's (1951) dream of using the policy sciences to better understand and improve democracy.

Part I showcases individual scholars and the works that have made major contributions to the literature. I asked senior scholars to present their views and interpretations of the pioneers of this field, largely guided by the belief that being their former students and/or collaborators gave them unique insight into ideas, context, and personalities. Bryan D. Jones contextualizes the early work of Cobb and Elder and the impact of their ideas. David A. Rochefort picks up where Jones leaves off and delves into more detail on Cobb's later scholarship, both via Rochefort's own collaboration with Cobb on problem definition and via Cobb's work on the cultural foundations of policy agendas. What stands out in both contributions is the spark that led to the creation of the field: the need to reconcile democratic theory and practice. It seems to me that the problems these pioneers stressed more than four decades ago continue to haunt us to the present day.

Having been one of his students gives Baumgartner unique insight into John Kingdon's contribution to agenda setting. Not only do Kingdon's ideas resonate in Baumgartner's own substantial scholarship on agenda setting, but his picture of the individual scholar is also a useful addition 
to understanding the nature of Kingdon's contribution. The picture that emerges is a lesson for all: one of imaginative intellect, broad interdisciplinary interests, and careful empirically based theorizing.

Part II deals with the development of theories. Junior and senior scholars have been asked to provide an overview of major approaches along with concepts, hypotheses, and main controversies. Each approach specifies different links between power and perception. Green-Pedersen and Princen outline the punctuated equilibrium approach. They discuss the main elements of the approach, hypotheses, and major developments that have propelled the literature forward since Baumgartner and Jones (1993) published their pioneering study. They also sketch a brief roadmap for future research. Cairney and Zahariadis do the same with multiple streams. They spell out some of the contributions and weaknesses of the literature since Kingdon's (1984) work. Unlike punctuated equilibrium, the literature on multiple streams seems to lack coherence or direction, giving it a garbage-can-like quality similar to the process that it aims to explain. Peterson and Jones report on a relative newcomer, the narrative policy framework. Linking the micro to the meso levels, they claim that policymaking consists mainly of competing narratives; that is, stories or scenarios that have settings, plot, characters, and a moral. Narratives are strategically used to affect policy decisions by manipulating the size and composition of coalitions. They do so by expanding (or restricting) the scope of conflict that, following Schattschneider (1960), increases (or decreases) the likelihood that some issues will be heard and others will not (McBeth et al., 2007). Finally, Saurugger outlines the constructivist perspective. The social construction of meaning is of paramount importance when seeking to understand the setting of agendas in public policy. Taking cues from Fischer (2003), discourse analysis and the subjective interpretation of symbols and identity are crucial elements in defining policy problems and proposing solutions. In fact, constructivism shares some common ground with the narrative policy framework in that it, too, focuses on narratives and how they are used to construct stories that explain why specific solutions are attached to particular problems.

Part III deals with ideas and actors in institutional contexts and delves into issues of perception and political power. Van Aelst and Walgrave explore the impact of the media in advocating and brokering ideas. They argue that the media frames issues and draws attention to important problems, but does not determine the agenda. In fact, the studies they review ascertain the constraining power of the media; that is, the media helps to keep issues off the agenda. In addition, they conclude that issue characteristics help galvanize the attention, but not the actions, of policymakers.

In the subsequent chapters in this section, Cohen, Chaqués Bonafont, 
and Novotný, Polášek, and Perottino look at particular classes of actors. Cohen examines the role and effects of policy entrepreneurs. Since Kingdon (1984), the literature has formally acknowledged the critical role that entrepreneurs play in the agenda setting process. Cohen puts forward several interesting propositions about when and how this happens. He connects four elements to stress the likelihood of entrepreneurial success (elements that move items up the docket or prevent others from reaching it): timing, skills, persuasion, and risk taking.

Chaqués Bonafont focuses on interest groups and their impact on agenda setting. Differentiating between insiders and outsiders, she reviews the rules of and barriers to access to show that the "pluralist heaven" is neither very pluralist nor particularly heavenly. Politics intervenes to structure relations in the form of power and perception. The capacity of interest groups to affect agendas, Chaqués Bonafont argues, is a function of coalition-building skills, venue shopping, and response agility.

Political parties play a special role in setting the agenda during "normal" legislative times. Novotný et al. address the impact of political parties on agenda setting. Viewing parties as organizations, they stress the multitude of conflicts that take place within each party, noting that the impact on agenda setting is contingent upon the time and role that parties - bureaucracies, members, and governing actors - play. They also note the link between elected officials and political parties, and stress the privileged position (and electoral calculus) between the two.

How are elections, media coverage, and parties linked to the agenda setting of formal political institutions? Rutledge contends that no other actor can shape the public and congressional agendas as forcefully as the US President can. Indeed, the literature indicates that the President has more power on the agenda setting stage than in the rest of the policymaking process. The literature makes three important points that certainly merit further investigation. First, presidential attention is institutionalized to a few politically expedient issues at a time. Second, presidents have far more influence over pointing to important issues than they have over "getting their way." Third, the President's relationship with the media is somewhat unspecified. It is not clear whether the President influences media attention or the media "forces" the President's hand. All in all, Rutledge's chapter reinforces a fundamental point made in the literature: the ability to set the government's agenda is a major component of political power in modern society.

Zittoun and Dunlop analyze the effects of ideas on agenda setting through culture, learning, and ideology. Adopting a constructivist perspective, Zittoun asks why and how issues come to be problems and how they gain the attention of policymakers. Building on political and cultural 
perspectives, Zittoun focuses on perceptions and argumentation to shed light on movement of ideas within and across agendas. He argues that labeling, causal stories, and victimhood are integral parts of the transformation of issues into public problems. To get onto the government's docket, problems must also be legitimized via ownership and "feasible" solutions. Dunlop narrows the scope of study and focuses more sharply on epistemic communities and knowledge in shaping the agenda. By generating new knowledge and promoting learning, epistemic communities have structural power over the agenda because they can "legitimately" redefine problems and link them to viable solutions. In this way, she connects perception (framing) to political power through learning.

Part IV reviews empirical applications across levels of government to highlight linkages between the four "P"s: power, perception, proximity, and potency. It is one thing to discuss theories and concepts but quite another to see how they are applied in concrete cases. I asked scholars to apply perspectives in single or multiple settings and in different national and international contexts to provide a "feel" for how agendas are set in specific contexts. At the national level, Eissler, Mortensen, and Russell explore the local government literature in multiple settings. Their conclusions are similar to those of national agenda setting research: there are similar theoretical orientations with minimal adaptation. Perhaps the main difference between local and national government agendas is the greater need for local consensus and the budgetary constraints, given their limited resources relative to national governments.

Peake addresses the topic of US foreign policy as a special case of agenda setting. He explores three different issue characteristics - salience (essentially proximity and potency), political power, and competition among issues - to show foreign policy agenda setting is unique only in terms of relative lack of information. Factors similar to those in domestic policy, such as the media, presidential perceptions, power, and issue characteristics, still affect how the agenda is set.

Shifting levels of analysis, Harcourt, Princen, and Joachim and Dalmer specify dynamics at the international level. The four "P"s are still important, although in different combinations: power and perception help to get things done, but proximity and potency play enhanced roles in mobilizing individual actors. Harcourt examines national-international interactions in cross-border broadcasting and data protection. She documents the activities of UK officials in pushing liberalization higher up the European Union (EU) agenda in these two areas. Applying the multiple streams approach, she explores four strategies used by policy entrepreneurs: mobilizing support, arousing interest, claiming authority, and 
building capacity. She stresses that timing and a pluralist style of interest representation made a big difference in facilitating UK activities.

Princen takes it up a step to explore agenda setting in a multilevel governance institution, the EU. Because the institutional make-up of the EU is quite open and multilayered, some concepts of theories crafted at the national level, such as venue shopping, are particularly appropriate at this level. The implication is that quite a few actors and institutions affect agenda access, making it even less controllable than national agendas but still elite-driven.

Joachim and Dalmer explore the process of agenda setting in a complex international organization: the United Nations (UN). Because international relations theory was initially used to study the functions and effectiveness of the UN, not much attention was given to agenda setting (the same can also be said for the EU). But the situation changed in the 1980 s and 1990s as the organization dropped the "shackles" of the Cold War and became free to take on more and more diverse issues. As a result of this issue growth, competition to access the UN agenda became more fierce and resource-heavy. At this point, non-governmental organizations (NGOs) got more involved not only in implementing UN policies but also in influencing the agenda. The authors explore one such issue, violence against women, to stress the important role NGOs play in framing, mobilizing structures, and taking advantage of opportunities, much like what happens in domestic politics.

Part V addresses the special case of crises. Most theorizing about agendas refers to "normal" politics. Agendas are set in routine fashion following relatively familiar protocols and processes. There are, however, periods of abrupt and turbulent change. During these periods of crisis, does agenda setting follow "normal" patterns? Experience tells us probably not, but it is not clear whether "normal" theory can incorporate these conditions. I approached scholars who deal with man-made crises and natural disasters to outline the literature as it relates to agenda setting and problem definition. The notion of crisis was left intentionally vague to capture the broadest possible range of phenomena. Agendas and the constituent process of problem definition are employed both as independent and dependent variables.

Birkland and Ansell, Boin, and Kuipers provide theoretical explications of crises and their effects on agendas. Birkland uses the concept of focusing events to explain agenda setting in a sub-class of crises: natural disasters. He offers a taxonomy of focusing events: "normal" (in Perrow's (1999) sense), novel, and normal under unusual circumstances. Using this taxonomy, he argues that potency and proximity are reasons why some natural disasters receive somewhat limited attention; for example, the lack 
of attention paid to earthquakes in comparison with hurricanes. But the political environment within which these crises/disasters occur also makes a big difference. Ansell et al. similarly use illustrative examples to craft a theoretical framework that takes crises seriously. Unlike Birkland, they examine institutional crises (gaps between what institutions promise and what they deliver) to understand their impact on policy agendas. Crises occur when these gaps are viewed as problematic because of potency, power, or perception. Institutionalization colors perceptions of crisis, which then limit (or expand) particular aspects of policy images to affect agendas, which in turn influence institutionalization. Crises may not lead to change partly because of elite efforts and institutional performance erosion over time.

Gava and Ladi are more empirically grounded and deal with two types of crises: financial and social. Gava addresses linkages between two different literatures: financial regulation and agenda setting. He argues that the intrusion of financial regulatory issues onto political and media agendas prior to the global financial crisis shaped frames and actor perceptions. However, during the crisis, peaks of attention were not necessarily followed by robust debates or policy change; rather, the crisis highlighted political tensions between regulators and the industry in an otherwise technical and off-limits sector. Ladi tackles problem definition within the context of a social issue: youth unemployment in Greece during the fiscal crisis of 2010-2015. Using the concepts of discursive institutionalism and critical junctures, she argues that crises, which are normally viewed as producing radical change, often do not. Perhaps the more interesting aspect of her study is the process labeled "non-decisions" (Bachrach and Baratz, 1963): crises actually suppress agenda access by limiting the impact of critical junctures, unlike Kingdon's (1984) multiple streams. Instead, they pave the way for responsibility drift and inaction.

\section{A PARTING PRESCRIPTIVE THOUGHT}

All contributors to this Handbook more or less share certain common objectives: the need to improve democratic theory and practice and the desire to draw implications from engaging in comparative and/or international research. It is hoped that readers will consider the following two implications in particular from the contributions to this book.

First, policy sciences have evolved over the years and seem to have moved away from the democratic incentive that originally served as the inspiration to create the field (deLeon, 1997). In the quest to become more scientific, scholarship appears to be less concerned with drawing implications to 
improve the policy functions of democracy. We attempt to rectify this situation. Our aim is not only to explain events or predict trends. It has a normative component as well: to improve democratic practice. In fact, the need to study agendas stems from the realization that the system is loaded and unbalanced (Bachrach and Baratz, 1962). We not only want to explain why and in what ways; we also aim to propose ways to fix it. This latter component is less frequently encountered than the former, but equally important in academic scholarship. It is hoped that this Handbook will provide readers with some reasons for this, as well as tools to redress this omission.

Second, all scholarship needs to become more explicitly comparative in method and international in scope. Studies must not only broaden their empirical content to appeal to a wider readership but also explore amendments and push the boundaries to escape cultural limitations. The term "globalization" is not just empty rhetoric but an analytical reality that has to be carefully theorized, investigated, and assessed. I have asked contributors to be as comparative as possible to tease out the benefits and limitations of agenda setting in different national settings, across levels of government, and under different conditions. The final product is a broader and analytically more nuanced policy approach. Readers are invited to draw their own conclusions as to whether we have succeeded in our endeavor. More importantly, readers are invited to develop and critically reflect on their own approaches to more fully understand the complexity of agenda setting in public policy.

\section{NOTE}

1. According to the Oxford Dictionary, the term "agenda" in the sense of "things to be done" originated in the early 17 th century (www.oxforddictionaries.com/definition/ english/agenda).

\section{REFERENCES}

Bachrach, P., and M. S. Baratz (1962), "Two faces of power", American Political Science Review, 56 (4), 947-952.

Bachrach, P., and M. S. Baratz (1963), "Decisions and non-decisions: An analytical framework", American Political Science Review, 57 (3), 632-642.

Baumgartner, F. R., and B. D. Jones (1993), Agendas and instability in American politics, Chicago, IL: University of Chicago Press.

Baumgartner, F. R., B. D. Jones, and J. Wilkerson (2011), "Comparative studies of policy dynamics", Comparative Political Studies, 44 (8), 947-972.

Birkland, T. A. (2004), "“The world changed today': Agenda-setting and policy change in the wake of September 11 terrorist attacks", Review of Policy Research, 21 (2), 179-200.

Braybrooke, D., and C. Lindblom (1963), A strategy of decision, New York, NY: Free Press. 
Cobb, R. W., and C. D. Elder (1971), "The politics of agenda-building: An alternative for modern democratic theory", Journal of Politics, 33 (4), 892-915.

Cobb, R. W., and C. D. Elder (1972), Participation in American politics: The dynamics of agenda-building, Baltimore, MD: The Johns Hopkins University Press.

Cobb, R. W., J. K. Ross and M. H. Ross (1976), “Agenda building as a comparative political process", American Political Science Review, 70 (1), 126-138.

Cohen, B. (1963), The press and foreign policy, Princeton: Princeton University Press.

Cohen, M. D., J. G. March, and J. P. Olsen (1972), "A garbage can model of organizational choice", Administrative Science Quarterly, 17 (1), 1-25.

deLeon, P. (1997), Democracy and the policy sciences, Albany, NY: State University of New York Press.

Demosthenes (1930), Orations: Volume I, trans. J. H. Vince, Loeb Classical Library 238, Cambridge, MA: Harvard University Press.

Fischer, F. (2003), Reframing public policy: Discursive politics and deliberative practices, Oxford, UK: Oxford University Press.

Green-Pedersen, C., and S. Walgrave (eds.) (2014), Agenda setting, policies, and political systems: A comparative approach, Chicago, IL: University of Chicago Press.

Holmes, M. D., and B. W. Smith (2008), Race and police brutality: Roots of an urban dilemma, Albany, NY: State of New York Press.

Huntington, S. (1968), Political order in changing societies, New Haven, CT: Yale University Press.

Jones, B. D., and F. R. Baumgartner (2005), The politics of attention: How government prioritizes problems, Chicago, IL: University of Chicago Press.

Kingdon, J. W. (1984), Agendas, alternatives, and public policies, Boston, MA: Little, Brown.

Lasswell, H. D. (1951), "The policy orientation", in D. Lerner and H. D. Lasswell (eds.), The policy sciences: Recent developments in scope and method, Stanford, CA: Stanford University Press, pp. 3-15.

Lippmann, W. (1922), Public opinion, New York, NY: Harcourt.

McBeth, M. K., E. A. Shanahan, R. J. Arnell, and P. L. Hathaway (2007), "The intersection of narrative policy analysis and policy change theory", Policy Studies Journal, 35 (1), 87-108.

McCombs, M. E., and D. L. Shaw (1972), "The agenda-setting function of mass media", Public Opinion Quarterly, 36, 176-187.

Perrow, C. (1999), Normal accidents: Living with high-risk technologies, Princeton, NJ: Princeton University Press.

Rogers, E. M., and J. W. Dearing (1988), "Agenda-setting research: Where has it been? Where is it going?", Communication Yearbook, 11, 555-594.

Schattschneider, E. E. (1960), The semi-sovereign people: A realist's view of democracy in America, New York, NY: Holt, Rinehart and Winston.

Smith, H. (2015), "Shocking images of drowned Syrian boy show tragic plight of refugees", The Guardian, September 2, available at www.theguardian.com/world/2015/sep/02/ shocking-image-of-drowned-syrian-boy-shows-tragic-plight-of-refugees (accessed 25 January 2016).

Zahariadis, N. (2014), "Ambiguity and multiple streams", in P. A. Sabatier and C. M. Weible (eds.), Theories of the policy process (3rd edn), Boulder, CO: Westview. 